\title{
A RARE CASE OF JEJUNOJEJUNAL INTUSSUSCEPTION AFTER SURGICAL REDUCTION OF ILEOCOLIC INTUSSUSCEPTION
}

\author{
Edin HUSARIĆ, Nešad HOTIĆ, Amir HALILBASIĆ
}

Department of pediatrics

University Clinical Centre Tuzla

Tuzla, Bosnia and Herzegovina

A five month old girl, with typical clinical, ultrasound and radiological signs of intussusception underwent surgery for ileocecocolic intussusception, with a long part of the colon involved. We performed manual reduction. The first two postoperative days passed normally, but over the next few days the content in the nasogastric tube increased. On the seventh postoperative day an abdominal $\mathrm{x}$-ray showed signs of abdominal obstruction (Fig. 1), and a new abdominal ultrasound revealed the typical target appearance. The clinical manifestation was intestinal obstruction without an abdominal palpable mass or bloody stool. We performed laparotomy which revealed jejunojejunal intussusception (Fig. 2). Postoperative jejunojejunal intussusception after the surgical reduction of ile-

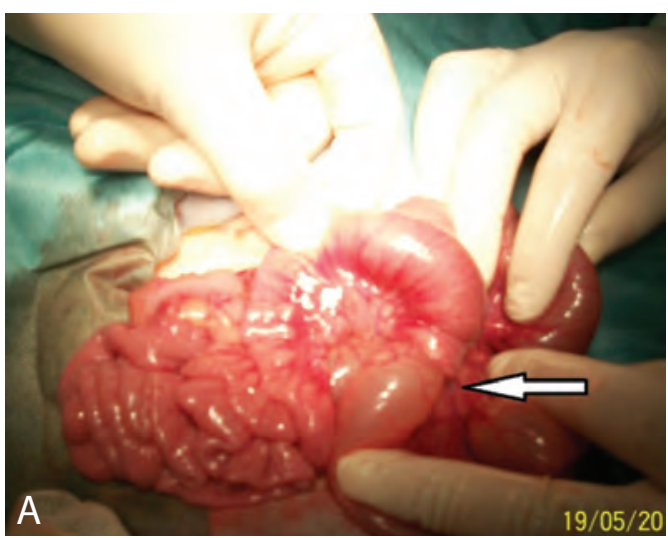

ocolic intussusception in infants and children is extremely rare and the clinical symptoms are not typical. The diagnosis of postoperative intussusception should be considered in

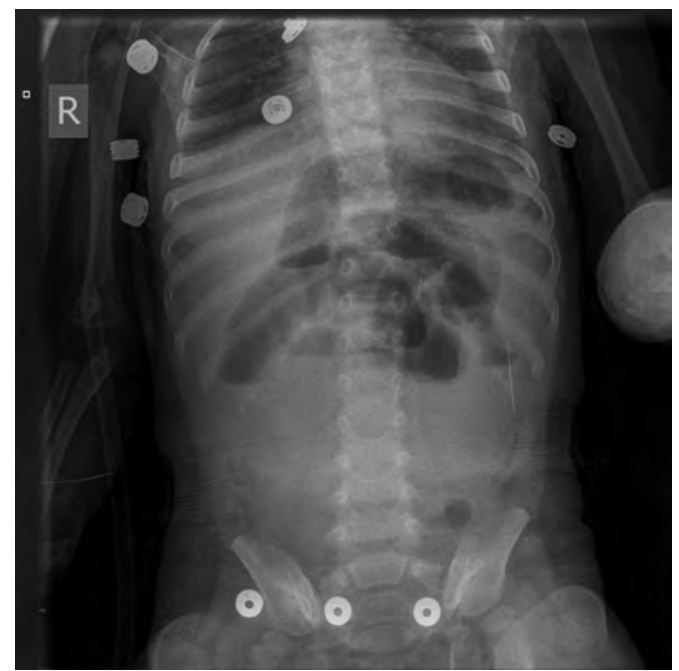

Fig. 1 Abdominal $x$-ray.

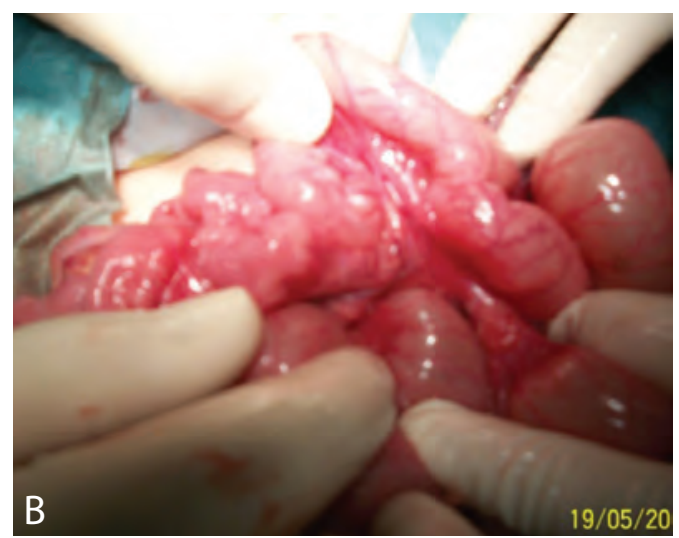

Fig. 2 Panel A: The jejunojejunal intussusception before manual reduction; Panel B: After manual reduction. 
children with signs of bowel dysfunction in the early postoperative period. A high index of suspicion and prompt laparotomy will usually allow manual reduction of the lesion. Diagnostic delay may result in bowel necrosis.

Key words: Jejunojejunal • Intussusception.

Authors' contributions: Conception and design: EH, $\mathrm{NH}$; Acquisition, analysis and interpretation of data: $\mathrm{AH}$; Drafting the manuscript: $\mathrm{EH}$; Revising it critically for important intellectual content: $\mathrm{EH}, \mathrm{NH}$.

Conflict of interest: The authors declare that they have no conflict of interest.
Corresponding author:

Edin Husarić

Department of pediatrics

University Clinical Centre Tuzla

75000 Tuzla

Bosnia and Herzegovina

hamir@bih.net.ba

Tel.: + 38735303 369; Fax.: + 38735250474

Received: May 20, 2014; Accepted: July 19, 2014

Copyright (C) 2014 by University Clinical Centre

Tuzla. E-mail for permission to publish:

paediatricstoday@ukctuzla.ba 